\title{
OPUS and CSRS Web-Based GNSS Services Accuracies For Data From USA and TURKEY
}

\author{
Tuna EROL
}

\begin{abstract}
Global Positioning System (GPS), which has entered every aspect of human life since its first appearance, has become widespread with introducing other systems (GLONASS, Galileo, BeiDou, QZSS, IRNSS, etc.). Today, all systems' common name, Global Navigation Satellite Systems (GNSS), continue to exist in our lives. While processing the GNSS data, scientific/academic, commercial software, and web-based applications are being used. Web-based services have become widespread very quickly since their introduction. Web-based services have provided ease of use, free of charge, results in a short period of time for users and eliminated the dependence on licensed software. Today, web-based evaluation services increase their activities, variety and number of users day by day. Research on the accuracy of the location obtained from these services continues. This study determined 42 stations in the United States of America and 18 stations in Turkey (with 10 - day good ionospheric conditions and 6 - day worse ionospheric conditions data sets) OPUS, CSRS web services in (depending on the duration of the session: 1 hour to 24 hours) evaluations were carried out. CSRS web service can evaluate GPS, GLONASS, Galileo data, but OPUS uses only GPS data. As can be seen from both the 1-hour results, it is thought that including GPS + GLONASS data in the evaluation has a positive effect. From the results we obtained, it was determined that 12 hours of observation should be made to good positioning accuracy under one $\mathrm{cm}$ using any of these applications. It has been determined that using the web-based GNSS evaluation services, good accurate positioning can be obtained from the data collected with a single receiver. But due to the publication time of precise ephemeris, as soon as the measurement is made, it is not possible to reach the mentioned accuracies. There are similar standards in the global world today and it can be said that a minimum of 2 hours of observation should be made for engineering applications. It has been determined that the web services used can reach the "high precision standard (horizontal 2 - $3 \mathrm{~mm}$, vertical 3 - $5 \mathrm{~mm}$ ) "defined by IGS with a minimum of 12 hours horizontally and 24 hours in vertical.
\end{abstract}

Keywords: CSRS; GNSS Evaluation; OPUS; Web-Based Services

\section{INTRODUCTION}

Global Positioning System (GPS), which has entered every aspect of human life since its first appearance, has become widespread with the introduction of other systems (GLONASS, Galileo, BeiDou, QZSS, IRNSS, etc.). Today, all systems' common name, Global Navigation Satellite Systems (GNSS), continue to exist in our lives. Various studies have attempted to determine the GPS position accuracy, especially from the day it existed to determine the accuracy depending on the base length and session duration.

The development of the satellite systems, the increase in the variety and the products that provide GNSS services (IGS; International GNSS Service, CODE; Center for Orbit Determination for Europe, JPL; NASA Jet Propulsion Laboratory, etc.) have contributed positively to position accuracy. When the system was first released, changes and innovations continued inevitably in measurement methods, estimation methods and software applied for positioning.

Various studies have attempted to determine the GPS position accuracy, especially from the day it existed. Eckl et al. in 2001 [1] showed that GPS-derived relative position sensitivity is a function of the distance between stations and observation time. They conducted the experimental study with the PAGES software, where the base distance was $26 \mathrm{~km}$ to $300 \mathrm{~km}$ and the observation time was 4 hours to 24 hours with 10 - day data of 1998 and for $n$ (North), $e$ (East), $u$ (Up) components and calculated the formulation. [1] similar studies to other researchers, Dong and Bock 1989 [2], Larson and Agnew 1991 [3], Feigl et al. 1993 [4] produced experimental formulation. Their study investigated the effect of distance when the base distance was less than $500 \mathrm{~km}(L<500 \mathrm{~km})$ during 7 - hour session periods. Observations of [2-4] were carried out before 1992 and with the existing GPS, a maximum observation time of 7 hours was possible. Beeti et al. 1999 [5] conducted different experiments on GPS sensitivity and accuracy for deformation control. Soler et al. [6] in their study in 2005, 5 USA CORS stations were used on OPUS (Online Positioning Service). They used 30 - day observation data with sub - 1, 2, 3 and 4 - hour observations. They obtained location accuracy based on observation time and presented a prediction function similar to Eckl [1] to the experimental formula. HÄKLI et al. [7] in their study, where GPS positioning accuracy was evaluated in 2008 based on interstation distance and observation time, evaluations for 2003 - 2005 for 10 to 24 hours observation time from 0.6 $\mathrm{km}$ to $1069 \mathrm{~km}$ on 10000 baselines were processed with Trimble Total Control commercial software. They have developed formulas on distance and observation time, and accuracy that can be achieved in broadcast or precise ephemeris. They have made comparisons with previous studies. Contrary to other results, short-term observations have shown that accuracy depends on the distance in their experimental results [7]. Sanlı and Engin [8] studied the accuracy of GPS positioning in over-regional areas in 2009. Geng et al. [9] in 2010 investigated the 7 - day data of 12 stations in Europe for the PPP strategy for the shortest observation periods (1, 2, 3 and 4) and optimal solution of ambiguity. They observed that they could reach the millimeter accuracy required for engineering applications with at least 3 hours of observation [9]. Tiryakioglu et al. [10] investigated the effects of number and duration of observations on positioning accuracy in measurement campaigns in 2010 to determine tectonic movements. According to the results obtained with the GAMIT/GLOBK software, it is necessary to perform at least 8 hours and repeated observations [10]. Öztürk and Şanlı [11] combined the two studies in 2011 and evaluated the accuracy of GPS position determination as a sensitive function both on a regional and global scale with GIPSY software on baselines from $3 \mathrm{~km}$ to $3000 \mathrm{~km}$ and compared the results [11]. Sanli and Kurumahmut [12] in the USA test network in 2011, 26 baselines were kept constant around $10 \mathrm{~km}$ and height difference varied from 50 meters to 1500 meters depending on the duration of the GPS 
observations (1, 2, 3, 4, 6, 8, 12 and 24 hours). Firuzabadi and King [13] tested the impact of reference stations' distribution on GPS positioning accuracy in 2011. They used 31 - day data from 2006 and used 1, 2, 3, 6, 12 and 24 - hour observation files and $26 \mathrm{~km}$ to $585 \mathrm{~km}$ baselines and GAMIT/GLOBK software from 2 to 16 reference stations. El-Mowafy [14] (2011) AUSPOS and CSRS-PPP tested the static processing results of the services. AUSPOS mm - $\mathrm{cm}$, CSRS-PPP dm level can be achieved with accuracy, he said. Rapinski and Cellmer [15] (2011) tested the performance of ASGEUPOS, AUSPOS and APPS services. There are no limitations on AUSPOS and APPS. But, for better results with ASG-EUPOS more than 720 epoch to must be use. Jha et al. [16] (2016) compared and interpreted the results of GPS online assessment services (OPUS and AUSPOS). Tariq et al. [17] (2017) compared and interpreted the results of GPS online evaluation services (OPUS and AUSPOS) and Leica Geo Office commercial software on short baselines in a fast static method. Isioye et al. [18] (2019) compared and interpreted the results of GPS web-based services on the test network (NIGNET) in Niger. Most of the research done so far is based on evaluations made with academic software or webbased services.

Nowadays, it has been shown that the accuracy of GNSS varies depending on the observation time. However, for this to happen, ambiguity should be solved, IGS precise ephemeris should be used and atmospheric effects between the base points should be eliminated.

Most of the research done so far is based on evaluations made with academic software. Of course, the results obtained with academic software are closest to the ideal because evaluation strategies take into account many different effects.

Web-based services have become widespread very quickly since their introduction. Web-based services have provided ease of use, free of charge results in a short time for users and eliminated the dependence on licensed software. Today, web-based evaluation services increase their activities, variety and number of users day by day. Research on the accuracy of the location obtained from these services continues. Web-based services often use academic software in the background.

This study determined 42 stations in the United States of America and 18 stations in Turkey (with 10-day and 6day data sets). OPUS (Online Positioning Service) and CSRS (Canadian Spatial Reference System) web services were used (depending on the duration of the session: 1 hour

to 24 hours) and evaluations were carried out. Firstly, Turkey and USA stations are almost at the same latitude, Fig. 4. Thus, the latitude effect has been ignored. Stations in the USA record only GPS data, stations in Turkey have gathered together GPS and GLONASS data.

Thereby, tested was the effect of including only GPS and GPS + GLONASS data in both web services evaluation. Accuracies obtained in Turkey and the USA (session duration, distribution of reference station, the accuracy obtained on a global scale, etc.) and evaluation strategies of web services were compared and interpreted for users.

\section{STUDY AREA AND BASELINES}

The stations and baselines used in the application consist of the California Spatial Reference Center (CSRC) and IGS network stations which are continuously monitoring the USA National Geodesy Network. The California Spatial Reference Center (CSRC) is responsible for "Establishing and maintaining an accurate state-of-theart network of GPS control stations for a reliable spatial reference system in California."

Table 1 Determined stations, baselines in the USA

\begin{tabular}{|c|c|c|c|c|}
\hline & & & & \\
\hline No & Station 1 & Station 2 & $\Delta s / \mathrm{km}$ & $\Delta h / \mathrm{m}$ \\
\hline 1 & dam2 & dam3 & 0.11 & 3 \\
\hline 2 & chil & p587 & 0.51 & 33 \\
\hline 3 & cvhs & wchs & 2.39 & 19 \\
\hline 4 & whc1 & rhcl & 4.37 & 83 \\
\hline 5 & holp & ceco & 6.27 & 10 \\
\hline 6 & uclp & wrhs & 12.38 & 104 \\
\hline 7 & elsc & cit1 & 14.03 & 154 \\
\hline 8 & uscl & dyh2 & 17.39 & 11 \\
\hline 9 & whe1 & pkrd & 21.23 & 37 \\
\hline 10 & long & $\mathrm{mhms}$ & 29.36 & 77 \\
\hline 11 & bkms & wrhs & 30.77 & 3 \\
\hline 12 & bran & spms & 44.91 & 39 \\
\hline 13 & azu1 & lbch & 47.03 & 172 \\
\hline 14 & nopk & mrdm & 48.20 & 295 \\
\hline 15 & cvhs & uclp & 49.88 & 8 \\
\hline 16 & wmap & spms & 59.98 & 61 \\
\hline 17 & clar & lfrs & 64.99 & 227 \\
\hline 18 & trak & wrhs & 69.03 & 108 \\
\hline 19 & sgdm & rock & 75.15 & 133 \\
\hline 20 & twms & lapc & 81.75 & 0 \\
\hline 21 & rock & lors & 85.79 & 104 \\
\hline 22 & lgwd & wmap & 91.22 & \begin{tabular}{|l|}
179 \\
\end{tabular} \\
\hline 23 & sfdm & psdm & 96.32 & 13 \\
\hline 24 & cnpp & cbhs & 99.33 & 16 \\
\hline 25 & spk1 & noco & 100.67 & 253 \\
\hline
\end{tabular}

Table 2 Determined stations and baselines in Turkey

\begin{tabular}{|c|c|c|c|c|c|c|c|c|c|}
\hline \\
\hline No & Station 1 & Station 2 & $\Delta s / \mathrm{km}$ & $\Delta h / \mathrm{m}$ & No & Station 1 & Station 2 & $\Delta s / \mathrm{km}$ & $\Delta h / \mathrm{m}$ \\
\hline 1 & svrt & ysst & 2 & 18 & 11 & slvr & terk & 55 & 90 \\
\hline 2 & beyk & pala & 15 & 69 & 12 & kcek & slvr & 59 & 15 \\
\hline 3 & kcek & pala & 18 & 48 & 13 & kcek & yali & 66 & 36 \\
\hline 4 & ista & svrt & 26 & 90 & 14 & pala & yali & 71 & 84 \\
\hline 5 & beyk & kcek & 33 & 21 & 15 & beyk & yali & 75 & 15 \\
\hline 6 & terk & yali & 37 & 39 & 16 & sile & terk & 80 & 32 \\
\hline 7 & pala & tuzl & 40 & 115 & 17 & beyk & slvr & 85 & 37 \\
\hline 8 & beyk & sile & 44 & 22 & 18 & istn & sary & 92 & 122 \\
\hline 9 & sile & tuzl & 48 & 24 & 19 & slvr & tuzl & 106 & 83 \\
\hline 10 & ista & tubi & 51 & 75 & & & & & \\
\hline
\end{tabular}

The CSRC was established in 1997 as a partnership with surveyors, engineers, GIS professionals, the National Geodetic Survey (NGS), the California Department of
Transportation (Caltrans), and the geodetic and geophysical communities.Stations (baseline lengths, 
height differences) (42) determined for the first application are presented in Fig. 1 and Tab. 1 below [19].

In the second part of the application, identified stations (18 base stations) in Turkey's Marmara region are located near Istanbul. These stations are located in TKGM-CORS
(Turkey National CORS Network) [20], ISKI-UKBS (Istanbul Municipality's Local CORS Network) [21] and IGS network. The determined stations, baselines, baseline lengths $(\Delta s)$ and height differences $(\Delta h)$ are as presented in Fig. 2, Fig. 3 and Tab. 2.

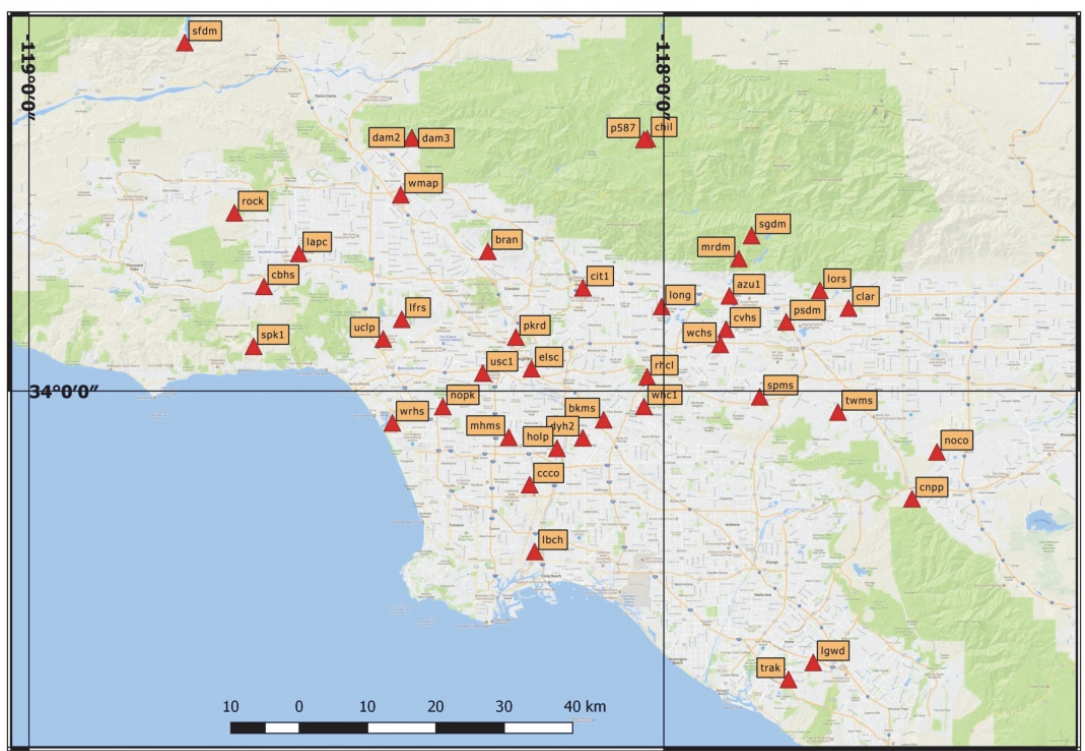

Figure 1 Stations determined in the USA and their distributions [19]
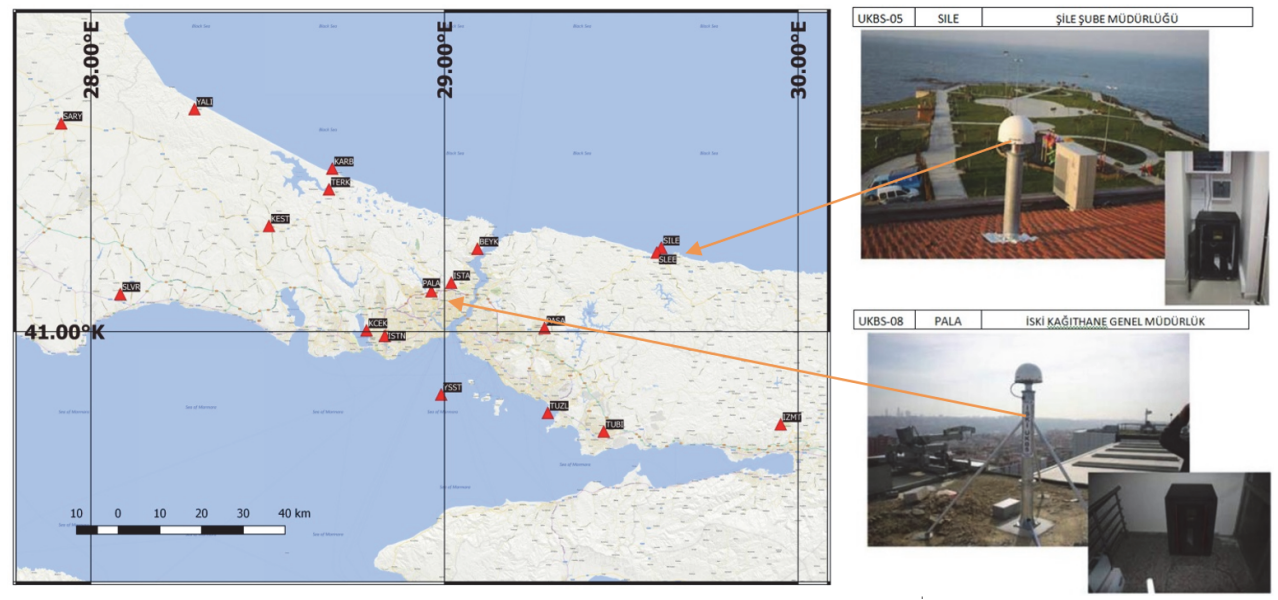

Figure 2 Stations determined in Turkey and their distributions $[20,21]$

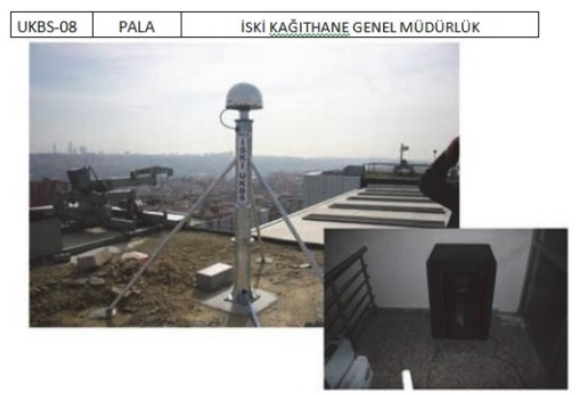

Figure 3 Sile and Pala stations [21]

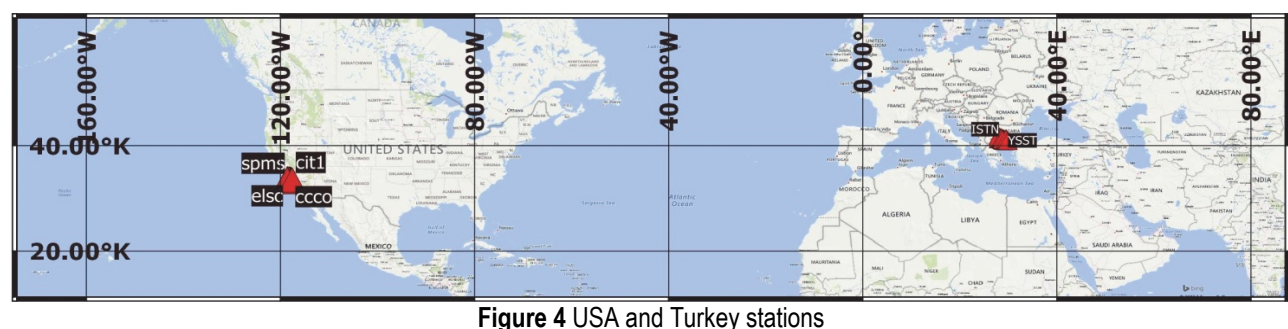

Figure 4 USA and Turkey stations 


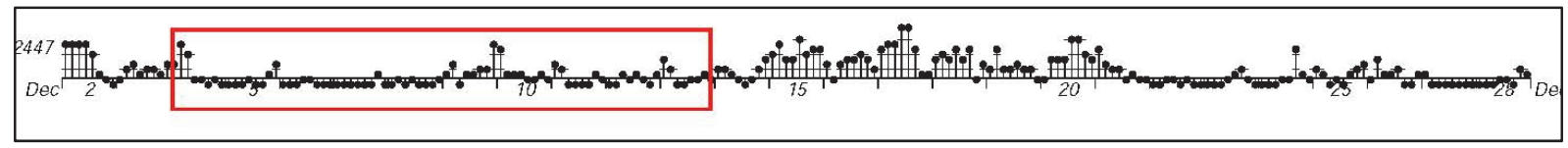

Figure 52012 December 4 to 13 Days KP Index Chart [24]

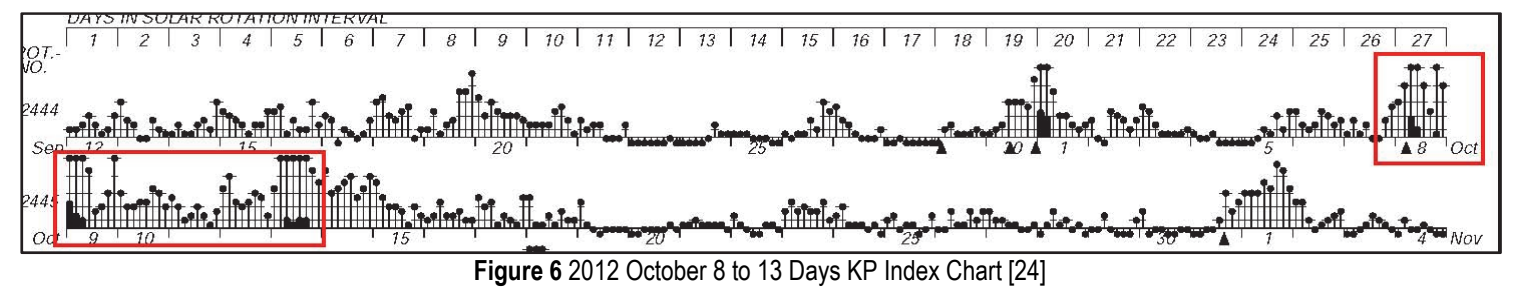

It was carried out together with the data's determination for which day of the year at the stations determined. Even if more suitable bases were identified, there was no data for the common day, so they were changed several times. www.solarham.net [22], www.swpc.noaa.gov [23] and www.gfz-potsdam.de [24] internet web sites and services were used to determine the most suitable day. Days 4 to 13 of December 2012 (338 to 347 GPS days; 10 days) were determined because there is common data for all stations. The ionosphere activity is minimum to create ideal conditions in Fig. 5.

According to the weather information received from weatherspark.com [25], it is determined that the weather is in the seasonal normal and there is no extreme situation. In the 10-day data set for our study (4 to 13 days of December 2012), it was determined that ionospheric activity (Kp index graphics from www.gfz-potsdam.de [24]) was at minimum and tropospheric activities (wheather forecast from weatherspark.com [25]) were at seasonal normals. This study aims to provide a clear indication of the GPS solution accuracy of web-based softwares with minimal atmospheric effects on GPS observations. Besides, 8 to 13 days (282 to 287 GPS days - 6 days) of October 2012, intended to test web services in poor ionospheric conditions, were also determined in Fig. 6. On the other hand, the high standard of the stations (IGS) used in the study, environmental impacts (Multipath, no signal interfering obstacles, etc.) and user errors (antenna installation, antenna height measurement errors, etc.) on the observation results have been very low or even negligible. Thus, it is aimed to demonstrate the accuracy of experiment-1 (USA stations), experiment-2 (Turkey stations) base solution results of commercial software clearly.

\section{USED SOFTWARE AND WEB-BASED SERVICES GIPSY-OASIS (Ver 6.4)}

GIPSY-OASIS, or GIPSY, is the GNSS-Inferred Positioning System and Orbit Analysis Simulation Software package. GIPSY is developed by the Jet Propulsion Laboratory (JPL) and maintained by the NearEarth Tracking Applications and Systems groups. GIPSYPPP, on the other hand, is the module that offers users the opportunity to locate with a single point precise location (PPP; Precise Point Positioning) method under the main software.The software is Linux-based and its use requires expertise.The software is only open to licensed users. It is not published for free. The exact coordinates of the stations in our study were obtained by evaluating the 24-hour sessions with GIPPYS-ppp.

OPUS (Online Positioning User Service), NOAA's (USA National Oceanic and Atmospheric Administration) Online Positioning User Service (OPUS) provides free access to high-accuracy National Spatial Reference System (NSRS) coordinates. OPUS uses software that computes coordinates using the NOAA CORS Network (NCN).

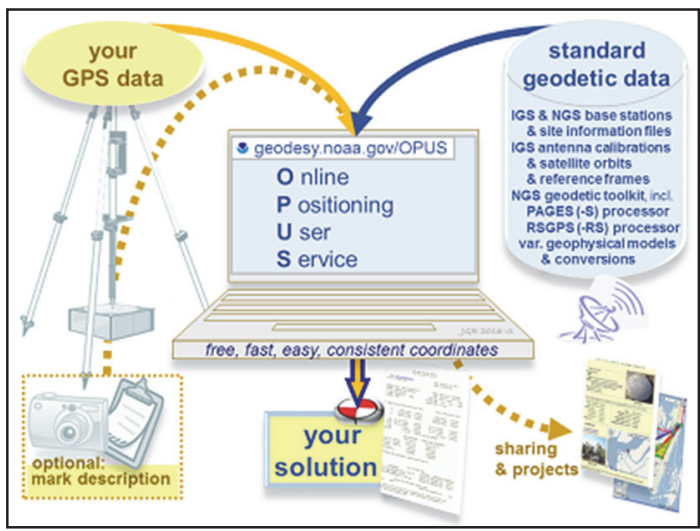

Figure 7 OPUS data evaluation process [26]

It provides the opportunity to evaluate the GPS observation data collected by users in a simple interface of the service, which can be accessed at any time of the day at https://www.ngs.noaa.gov/OPUS/index.jsp Fig. 7 [26]. Data entry to OPUS by the user is done in 5 steps. 1-upload observation file(s), 2 - define antenna model, 3 - enter antenna height, 4 - enter e-mail address, 5/6 - upload to the server with one of the rapid static or static options. The solution file calculated by the system is sent to the e-mail address entered by the user.

During the usage of OPUS in 5 steps, the following points should be considered. 1-Data should be collected with a dual-frequency GPS $(L 1 / L 2)$ receiver. 2 - Only static observations are processed by the system. The antenna should not be moved during the observation. 3 - Minimum 15 minute and maximum 48 hour data (not to be exceeded more than 1 midnight) are used by the system. The data presented as 4 - Fast-Static solution, should include P2, P1 or $\mathrm{C} 1$ observations. 5-GLONASS or Galileo can be observed and included, but only GPS data is used.

CSRS (Canadian Spatial Reference System), Natural Resources Canada's Canadian Geodetic Survey (CGS) provides Canadian Spatial Reference System (CSRS) Precise Point Positioning (PPP) web service [27] allows the computation of higher accuracy positions of raw Global 
Navigation Satellite System (GNSS) data. It provides services to users with a simple interface.

Users must register for the system free of charge. The system allows to collect data static or kinematic mode in the NAD83 or ITRF datum and the user preferred vertical datum. As an additional option, it allows the users to define the ocean loading files (in the appropriate format by the system) of the station they are measuring.

The service can be evaluated with single or dualfrequency receivers, static or PPP (Precise Point Positioning) technique kinematic measurements in RINEX format (gzip, zip, unix compression single or multiple files) GNSS data (GPS, GLONASS, Galileo). CSRS-PPP application uses the most appropriate of Final, Rapid or UltraRapid satellite ephemeris (FINAL, RAPID or ULTRA-RAPID). FINAL (+/-2 cm): combined weekly and available $13-15$ days after the end of the week, RAPID $(+/-5 \mathrm{~cm})$ : available the next day, ULTRA RAPID $(+/-15$ $\mathrm{cm})$ : available every 90 minutes. However, if GPS + GLONASS data will be used together, this period increases to 3 hours.

The system sends the solution link to the users in 4 different file formats (* .csv, ${ }^{*}$.pdf, ${ }^{*}$.pos, ${ }^{*}$.sum). Result files that are not downloaded within 48 hours are automatically deleted by the system. The system also offers users the opportunity to send observation files and get evaluation results with the desktop application it offers.

\section{GNSS DATA ANALYSIS}

SOPAC; The Scripps Orbit and Permanent Array Centre serves as data archives for SCIGN (The Southern California Integrated GPS Network). SOPAC archives GPS site RINEX (Receiver Independent Exchange
Format) files each day for SCIGN and other regional GPS networks. SOPAC is an International GNSS Service (IGS) [28] Global Data Centre and provides and calculates other IGS products such as polar motion, precise satellite orbits and Earth rotation variations. SOPAC generates time series of daily three-dimensional positions for the global permanent GNSS stations with respect to the ITRF (International Terrestrial Reference Frame). SOPAC browsers were used at http://sopac.ucsd.edu/ [19] to download the GPS data of the permanent GPS stations used in experiment-1. The locations of the permanent GPS stations used in this study are shown in Fig. 1, Tab. 1. The stations presented in Fig. 2, Fig. 3 and Tab. 2 were obtained from TKGM-CORS [20] and ISKI-UKBS [21] web service. The GPS data was obtained in the RINEX format and sampled with a 15 degree elevation cut-off angle and 30 second recording intervals.

Observation files were downloaded from SOPAC, TKGM-CORS and ISKI-UKBS archives. Each observation data was subdivided into mutually nonoverlapping 1 h, 2 h, 3 h, 4 h, 6 h, 8 h, 12 h sessions.

First, the exact positions of the stations were obtained by the average of the values obtained from the GIPSY-PPP (ver 6.4), $24 \mathrm{~h}$ observation data from all the stations:

- All observation sessions ( 1 h, 2 h, 3 h, 4 h, 6 h, 8 h, 12 $\mathrm{h}$ and $24 \mathrm{~h}$ ) were processed using web services OPUS and CSRS.

- Minimum Observation Session Duration: 60"

- Ephemeris: Precise

- Satellite System: USA Stations (GPS), TURKEY Stations (GPS+GLONASS)

- Process: Auto Mode (CSRS; Precise Point Positioning, OPUS; Relative Baseline Solution).

- All processes were based on fixed solution.

Table 3 Number of planned and realized observations

\begin{tabular}{|c|c|c|c|c|c|c|}
\hline & CSRS-PPP & CSRS-PPP & \multirow{2}{*}{$\begin{array}{l}\text { Solution } \\
\text { Ratio }\end{array}$} & OPUS & OPUS & \multirow{2}{*}{$\begin{array}{l}\text { Solution } \\
\text { Ratio }\end{array}$} \\
\hline & $\begin{array}{c}\text { Number of } \\
\text { processing Planned }\end{array}$ & $\begin{array}{c}\text { Number of processing } \\
\text { Realized }\end{array}$ & & $\begin{array}{c}\text { Number of } \\
\text { processing Planned }\end{array}$ & $\begin{array}{c}\text { Number of processing } \\
\text { Realized }\end{array}$ & \\
\hline USA (42 stations) & 40320 & 39584 & $98 \%$ & 40320 & 38985 & $97 \%$ \\
\hline TURKEY(42 stations) & 16320 & 15900 & $97 \%$ & 16320 & 8709 & $53 \%$ \\
\hline SUMMARY & 56640 & 55484 & & 56640 & 47694 & \\
\hline
\end{tabular}

Table 4 Evaluation strategies of used software and web-services

\begin{tabular}{|c|c|c|c|c|c|c|c|}
\hline Software & Organization & $\begin{array}{l}\text { Software } \\
\text { and } \\
\text { GNSS }\end{array}$ & $\begin{array}{l}\text { Solution } \\
\text { Method }\end{array}$ & $\begin{array}{l}\text { Supported } \\
\text { Data Type }\end{array}$ & Data Upload & Coordinates & Used Stations \\
\hline $\begin{array}{l}\text { GIPSY-ppp } \\
\text { (Ver 6.4) }\end{array}$ & NASA JPL & $\begin{array}{l}\text { Gipsy-ppp } \\
\text { (Ver 6.4) } \\
\text { GPS }\end{array}$ & $\begin{array}{l}\text { Absolute } \\
\text { PPP }\end{array}$ & Rinex (Linux) & Ftp & $\begin{array}{l}\text { Coordinates and error } \\
\text { values in measuring } \\
\text { epoch }\end{array}$ & PPP \\
\hline CSRS-PPP & $\begin{array}{l}\text { Natural Resources } \\
\text { Canada }\end{array}$ & $\begin{array}{l}\text { NRCan-ppp } \\
\text { GPS } \\
\text { GLONASS } \\
\text { Galileo }\end{array}$ & $\begin{array}{l}\text { Absolute } \\
\text { PPP }\end{array}$ & Rinex & $\begin{array}{l}\text { Ftp, } \\
\text { www, } \\
\text { PC app. }\end{array}$ & $\begin{array}{l}\text { Geographic, } \\
\text { Cartesian and UTM } \\
\text { coordinate and square } \\
\text { mean error }\end{array}$ & PPP \\
\hline OPUS & $\begin{array}{l}\text { American National } \\
\text { Geodetic Survey } \\
\text { NGS }\end{array}$ & $\begin{array}{l}\text { PAGES } \\
\text { GPS }\end{array}$ & Relative & $\begin{array}{l}\text { Rinex } \\
\text { Z file, zip, gzip, } \\
\text { pkzip }\end{array}$ & Www & $\begin{array}{l}\text { Geographic, } \\
\text { Cartesian and UTM } \\
\text { coordinate and square } \\
\text { mean error }\end{array}$ & $\begin{array}{l}9 \text { stations Rapid } \\
\text { Static, } \\
3 \text { stations static }\end{array}$ \\
\hline
\end{tabular}

The average position from the ten $24 \mathrm{~h}$ sessions was then adopted as the 'true' position of the point. For each baseline, the differences in north, east and height from this true position were determined for every observing session. The RMS values of each component were then computed for each baseline distance and each value of T. Any individual component of a positional difference that exceeded its corresponding RMS value by more than a factor of three was discarded as an outlier and the corresponding RMS value was recomputed. Tab. 2 presents the outlier statistics. The planned and realized evaluations are presented in Tab. 3 .

Our experience is based only on GNSS observations. It is not supported by other measurement techniques (VLBI; 
Very Long Baseline Interferometry, SLR; Satellite Laser Ranging, EDM; Electronic Distance Measurement). The accuracy obtained as a result of our experiment reflects the internal accuracy of the GNSS. Data evaluation strategies of the software and services used are presented in Tab. 4

\section{RESULTS}

Within the scope of the experiment, 103.178 evaluation results were compiled with CSRS-PPP and OPUS web services. Stations in the United States (42) and stations in Turkey (18) for evaluation results were obtained. The following results in Fig. 8, Fig. 9 and Fig. 10 were obtained for the three components North $(n)$, East $(e)$ and $\operatorname{Up}(u)$ for 10 days (suitable ionospheric conditions) and 6 days (worse ionospheric conditions) periods.

In the charts presented in Fig. 8, Fig. 9 and Fig. 10, the

"Pred.Eckl vd. " column; calculated from the following prediction formula obtained by Eckl et al. in 2001[1].
$S_{e}=k_{e} / T^{0.5}, k_{e}=9.9 \pm 3.1 \mathrm{~mm} \cdot h^{0.5}$

$S_{u}=k_{u} / T^{0.5}, k_{u}=36.5 \pm 9.1 \mathrm{~mm} \cdot h^{0.5}$

"Pred.T.Soler vd." column; it was calculated from the following:

$$
R M S(\mathrm{~cm})=\frac{k}{\sqrt{T}}\left\{\frac{k=1.0 ; \text { horizontal }(\text { northandeast })}{k=3.7 ; \text { vertical }}\right.
$$

prediction formula obtained in 2005 by Soleret al.[6], Eckl et al.[1] did their study for observations from 4 to 24 hours. With the formula they obtained, the estimated accuracy values for the observations from 1 hour to 3 hours were also calculated and added to the chart.

$$
S_{n}=k_{n} / T^{0.5}, k_{n}=9.5 \pm 2.1 \mathrm{~mm} \cdot h^{0.5}
$$

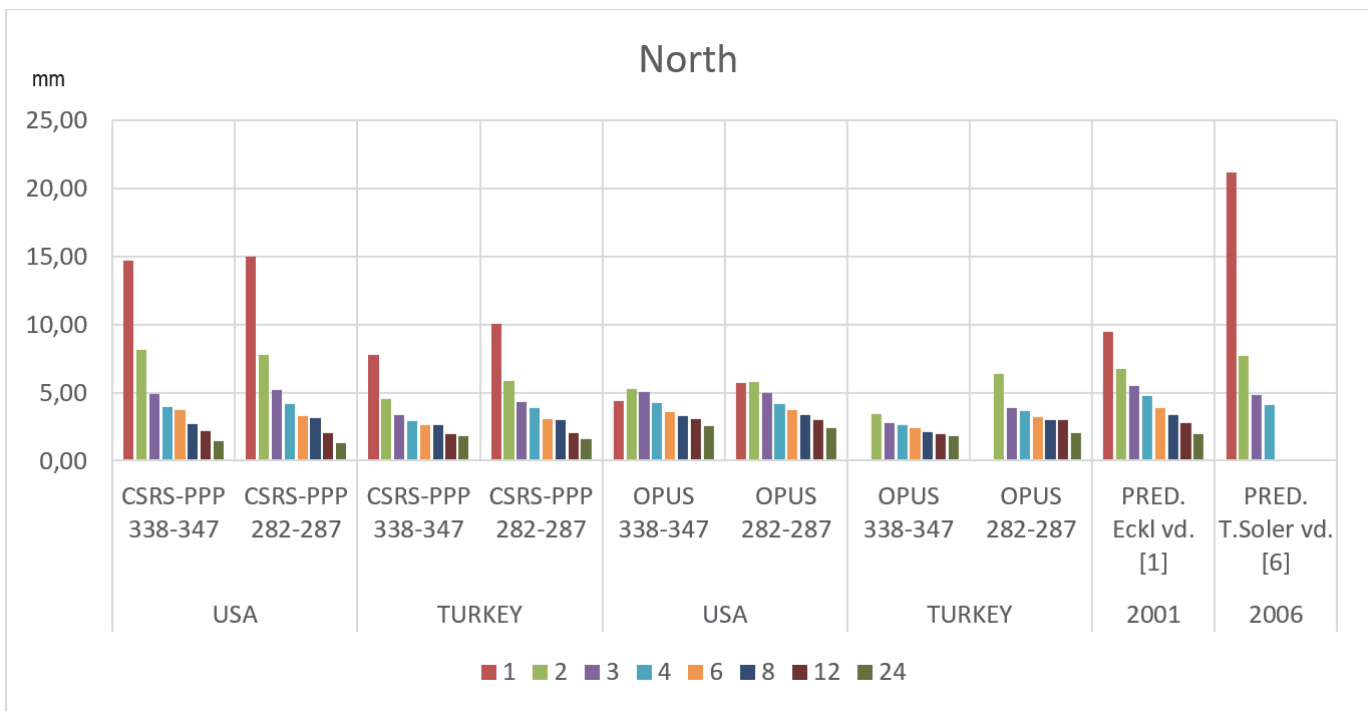

Figure 8 OPUS and CSRS-PPP web service solutions north $(n)$ component results

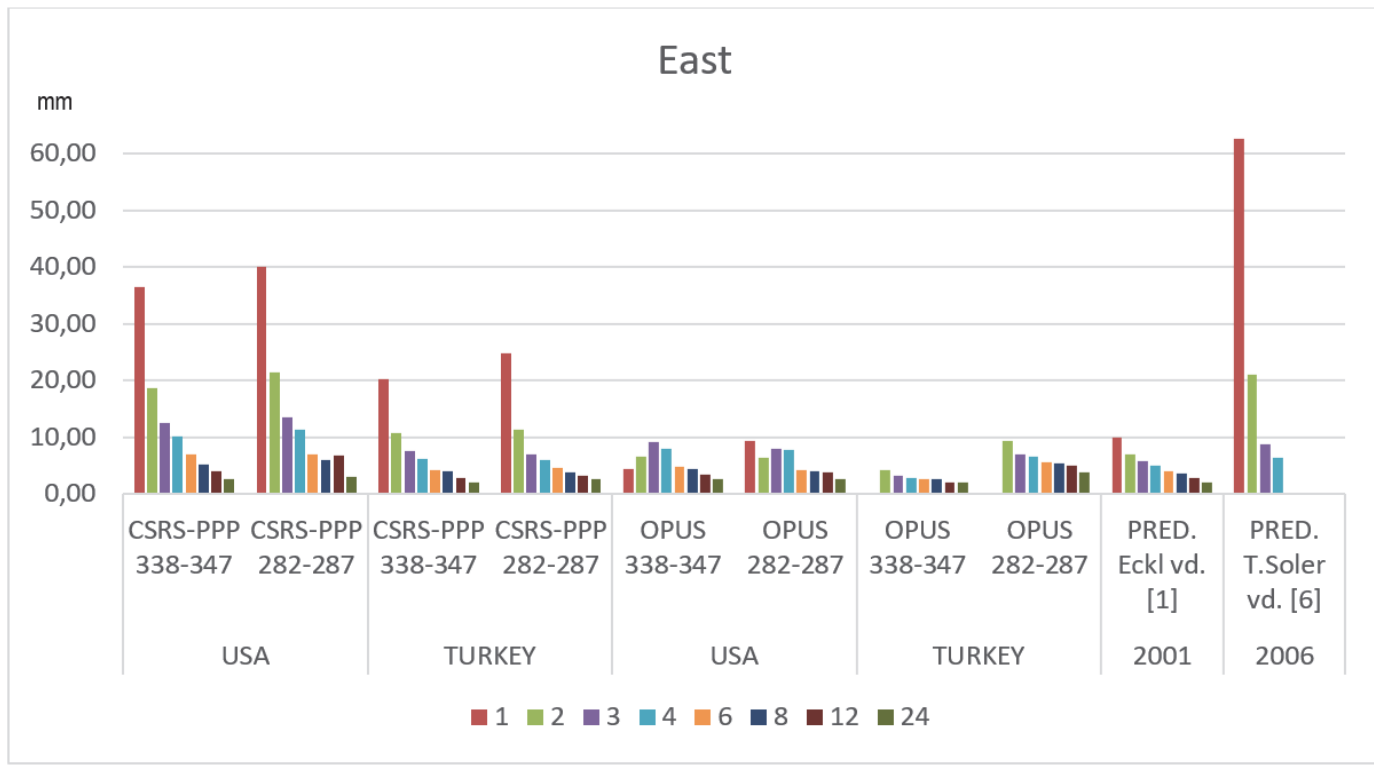

Figure 9 OPUS and CSRS-PPP web service solutions east (e) component results 


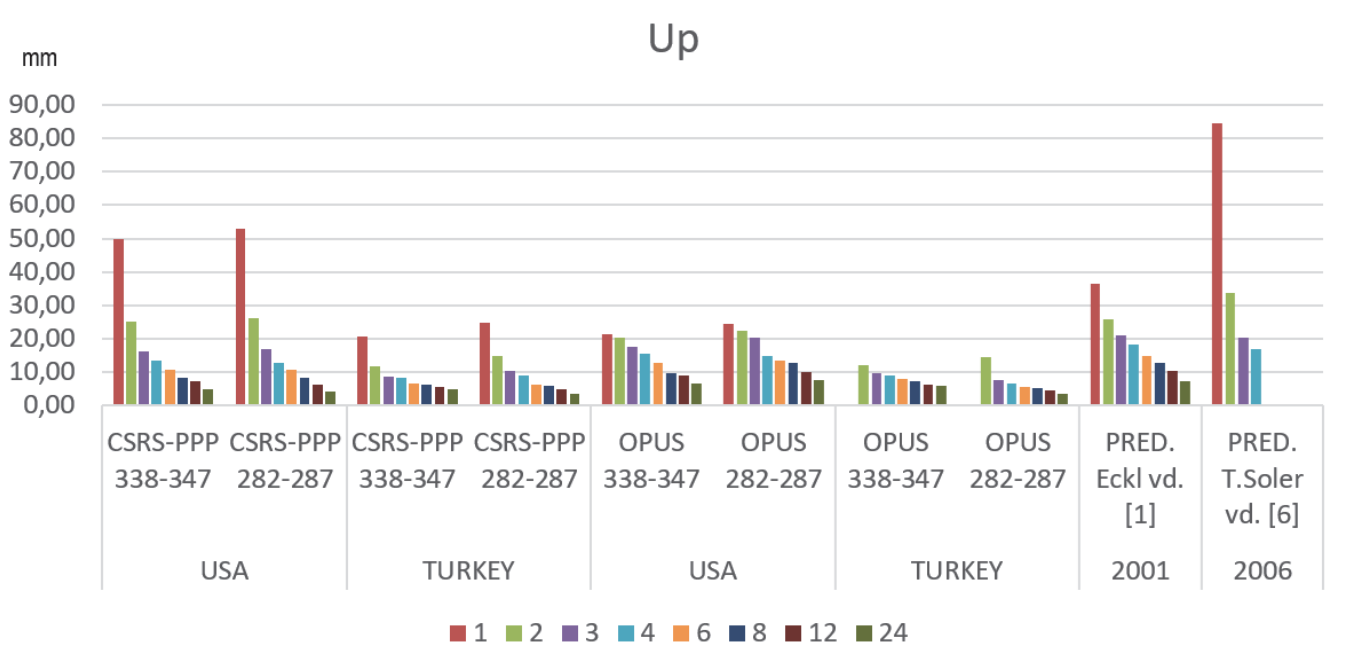

Figure 10 OPUS and CSRS-PPP web service solutions up $(u)$ component results

$S_{n}, S_{e}, S_{u}$ are standard errors (RMS values) on North, East and Up components. $k_{n}, k_{e}, k_{u}$ are predicted constants, $T$ and $h$ are observation time in formula 1,2 and 3.

$k$ is predicted constant, $T$ is observation time in Eq. (4).

Within the study's scope, 113.280 (for OPUS 56640, for CSRS 56640) evaluations were designed but solution result could be obtained for 103.178 units. $98 \%$ of the planned assessments was made for CSRS and $84 \%$ for OPUS Tab. 3. In the first step of the application, the exact values of all stations X, Y, Z (ITRF 2008) were obtained from the 10 day and 6 day averages of the 24 hour data of the stations determined by the academic software GIPSYPPP (Ver 6.4).

CSRS and OPUS Web-Based services' average results from one hour to four-hour observations (n, e, u) in the United States and Turkey, respectively:

- CSRS-USA; $14.74 \mathrm{~mm}, 36.58 \mathrm{~mm}, 49.91 \mathrm{~mm}$ (10 days; minimum ionospheric conditions), $15.02 \mathrm{~mm}, 40.02 \mathrm{~mm}$, $52.97 \mathrm{~mm}$ (6 days; worse ionospheric conditions).

- CSRS-Turkey; $7.77 \mathrm{~mm}, 20.25 \mathrm{~mm}, 20.58 \mathrm{~mm}$ (10 days; minimum ionospheric conditions), $10.04 \mathrm{~mm}, 24.75 \mathrm{~mm}$, $24.74 \mathrm{~mm}$ (6 days; worse ionospheric conditions).

- OPUS-USA; $4.39 \mathrm{~mm}, 4.40 \mathrm{~mm}, 21.32 \mathrm{~mm}$ (10 days; minimum ionospheric conditions), $5.74 \mathrm{~mm}, 9.29 \mathrm{~mm}$, $24.38 \mathrm{~mm}$ (6 days; worse ionospheric conditions).

It is known that most of the ionospheric effect is eliminated if dual-frequency receivers are used. But, although PPP or relative evaluation was made, increased ionospheric activity (282 to 286 GPS days in our application) was found to have a negative effect on the results. In particular, this effect was found to be more on the vertical component. It has been determined that after 6 hours of observation time, the ionospheric effect decreases considerably with increasing observation time, but it should be taken into consideration in short-term observations.

OPUS-Turkey; OPUS web service uses the rapid static evaluation method for observation times (15 minutes to 2 hours) under 2 hours. In this method, the OPUS NOAA determines the positioning from the Cors network by making the base solution with the 9 closest/suitable stations. Because there is no possibility of retrieving data from the OPUS web service Cors stations in Turkey, it has not produced the solution for 1 hour observations.

CSRS web service can evaluate GPS, GLONASS and Galileo data (Tab. 4). Stations in the United States collect only GPS data, but most stations in Turkey are collecting data in both GPS and GLONASS.

CSRS evaluation process (for Turkey stations) GLONASS data were included in the evaluation. As can be seen from both the 1-hour results and the results in Fig. 8, Fig. 9 and Fig. 10, it is thought that including GPS + GLONASS data in the evaluation has a positive effect.

The results show that 12 hours of observation should be made to reach positioning accuracy under one $\mathrm{cm}$ using any of these applications.

\section{CONCLUSIONS}

In the evaluations made over the years for online applications (2001 Eckl et al. and 2005 T. Soler solution results presented in the graphics; Eckl et al. used PAGES academic software in their studies, T. Soler et al. used OPUS.), it was determined that the position accuracy obtained was increased. The reasons for the increase of positioning accuracy: the developments in software, the introduction of other satellite systems besides GPS (GLONASS data was also used for our application), improvements in modeling, the inclusion of models with more effects in the evaluation process and application of new evaluation techniques (PPP; Precise Point Positioning) can be listed.

It has been determined that the absolute position determination method, which could not be used before in applications requiring high accuracy, has made significant progress with the PPP technique. Thus, it has been seen that precise positioning information can be reached with a single receiver.

Different ionospheric conditions (Fig. 5 and Fig. 6) were tested in two different time periods determined in practice. It is known that the effect of the ionosphere on GNSS signals depends on the electron density in the ionosphere and this situation is related to solar radiation. Since GNSS signals are weakly structured signals, they can be subject to signal interference electronically. Although a 
difference in ionospheric activity between the days was determined, as seen in Fig. 5 and Fig. 6, it did not cause an interruption in the signals at the stations whose data were used. Besides, interruptions in GNSS signals may occur at high levels of ionospheric activities. In this case, especially when short-term observations are made, a certain period of time is required for recalculation to solve the initial integer uncertainty, which may cause accuracy losses. The disadvantage of the PPP method, known as the convergence time, is more important (compared to the relative method) so that the observation is not interrupted. Users need to follow sudden changes in the weather. Users check the organizations' weather reports during the planning phase (to not interrupt GNSS signals).

In the experiment, both satellite systems (GPS/GLONASS) were used for evaluation. Participation of other satellite systems in data evaluation processes will contribute positively in the future. For this reason, both software producers and hardware (receiver antenna companies) will have to update themselves with new satellite systems.

It has been determined that using the web-based GNSS evaluation services, good accurate positioning can be obtained from the data collected with a single receiver. These services turn all available GNSS receivers into a mobile receiver, increasing the productivity and reducing the time of the measurements.

As soon as the measurement is made, it is not possible to reach the above-mentioned accuracies. This situation is also expressed on the pages of web-based services. Again, these services are free for all users (casual, classic geodetic applications, engineering studies or high precision works), do not require installation (web-based), and provide location information with simple usage.

Geodetic engineering for daily application in Turkey using one of these services, to achieve the expected accuracy on the location of the technical regulations is necessary to measure at least 2 hours. Since there are similar standards in the global world today, it can be said that a minimum of 2 hours of observation should be made for engineering applications.

In terms of relative evaluation of OPUS service, similar accuracy positioning was obtained in two different geographies (USA and Turkey), although the number of reference stations (such as shorter distance between stations, other alternative stations) was higher in the USA. It was determined that the accuracy was close to each other even in short observation times regardless of the reference station distance on a global scale.

This standard generally refers to the standard desired to be achieved in studies that require very high accuracy (such as crust movements, deformation measurements, IGS scale measurements, etc.). In order to reach these high standards, evaluations are generally done in relative terms and session times are quite long (12 or 24 hours).

It has been determined that the web services used can reach the "high precision standard" defined by IGS with a minimum of 12 hours horizontally and 24 hours vertically.

\section{Acknowledgements}

I am grateful to NASA's Jet Propulsion Laboratory for providing the GIPSY OASIS-PPP (Ver6.4) software
(Experiments with GIPSY were carried out in Yildiz Technical University Laboratory) and for satellite orbit and clock solution files. I also thank the Scripps Orbit and Permanent Array Centre (SOPAC) researchers for opening their archives to scientific activities worldwide. I would like to thank the Istanbul Water and Sewerage Administration (ISKI) and the General Directorate of Land Registry and Cadastre (TKGM) for the second experiment data. Thanks to the German Research Center For Geoscience (GFZ) managers and employees for atmospheric data. Thanks to Officials Topcon Turkey for offering unlimited use of the TOPCON Magnet program. The maps in Fig. 1 and Fig. 2 were created with the opensource QGIS program and Bing map. Thank you to them too.

\section{REFERENCES}

[1] Eckl, M. C., Snay, R. A., Soler, T., Cline, M. W., \& Mader, G. L. (2001). Accuracy of GPS-derived relative positions as a function of interstation distance and observing-session duration. Journal of Geodesy, 75, 633-640. https://doi.org/10.1007/s001900100204

[2] Dong, D. N., \& Bock, Y. (1989). Global Positioning System Network Analysis with Phase Ambiguity Resolution Applied to Crustal Deformation Studies in California. $J$. Geophys. Res., 94(B4), 3949-3966. https://doi.org/10.1029/JB094iB04p03949

[3] Larson, K. M., \& Agnew, D. C. (1991). Application of the global positioning system to crustal deformation measurement. Precision and accuracy. J. Geophys. Res. 96(B10), 16547-16565. https://doi.org/10.1029/91JB01275

[4] Feigl, K. L., Agnew, D. C., Bock, Y., Dong, D., Donellan, A., Hager, B. H., Herring, T. A., Jackson, D. D., Jordan, T. H., King, R. W., Larsen, S., Larson, K. M., Murray, M. H., Shen, Z. K., \& Webb, F. H. (1993). Space geodetic measurement of crustal deformation in central and southern California, 1984-1992. J Geophys Res, 98(B12), 21 677-21 712. https://doi.org/10.1029/93JB02405

[5] Betti, B., Biagi, L., Crespi, M., \& Riguzzi, F. (1999). GPS sensitivity analysis applied to non-permanent deformation control Networks. J. Geodesy, 73, 158-167. https://doi.org/10.1007/s001900050231

[6] Soler, T., Michalak, P., Weston, N. D., Snay, R. A., \& Foote, R. H. (2005). Accuracy of OPUS solutions 1- to 4-h observing sessions. GPS Solut, 10(2006), 45-55. https://doi.org/10.1007/s10291-005-0007-3

[7] Hakli, P., Kovvula, H., \& Puupponen, J. (2008). Assessment of Practical 3-D Geodetic Accuracy for Static GPS Surveying. Integrating Generations FIG Working Week, 1419 June 2008, Stockholm, Sweden.

[8] Sanli, D. U. \& Engin, C. (2009). Accuracy of GPS Positioning Over Regional Scales. Survey Review, 41(312), 192-200. https://doi.org/10.1179/003962609X390094

[9] Geng, J., Meng, X., Teferle, R. N., \& Dodson, A. H. (2010). Performance of precise point positioning with ambiguity resolution for 1- to 4-h observation periods. Surv Rev 42, 155-165. https://doi.org/10.1179/003962610X12572516251682

[10] Tiryakioğlu, İ., Dereli, M. A., Erdoğan, S. Ve Gülal, E., (2010). Tektonik Hareketlerin Belirlenmesine Yönelik Ölçü Kampanyalarında GNSS Gözlem Sayı ve Sürelerinin Konum Doğruluğuna Olan Etkilerinin Araştırılması. Harita Teknolojileri Elektronik Dergisi 2010, 2(2), 32-38.

[11] Ozturk, D. \& Sanli, D. U. (2011). Accuracy of GPS Positioning from Local to Regional Scales: A Unified Prediction Model. Survey Review, 43(223), 579-589. https://doi.org/10.1179/003962611X13117748892191 
[12] Sanl1, D. U. \& Kurumahmut, F., (2011). Accuracy of GPS Positioning in the Presence of Large Height Differences. Survey Review, 43(320), 162-176. https://doi.org/10.1179/003962611X12894696204948

[13] Firuzabadi, D. \& King, R. W. (2012). GPS Precision as a Function of Session Duration and Reference Frame Using Multi-Point Software. GPSSolutions, 16, 191-195. https://doi.org/10.1007/s10291-011-0218-8

[14] El-Mowafy, A. (2011). Analysis of web-based gnss postprocessing services for static and kinematic positioning using short data spans. Survey Review, 43(323), 535-549. https://doi.org/10.1179/003962611X13117748892074

[15] Rapinski, J. \& Cellmer, S. (2011). Tests of selected automatic positioning systems in post-processing mode. Technical Sciences, 14(1), 45-56.

[16] Jha, M. K., Singh, S., Upadhyay, N., \& Khare, N. (2016). Comparative study of online gps postprocessing services and effects on dgps data processing. International Research Journal ofManagement Science Technology, 7(1), 29-35.

[17] Tariq, M., Hadi, A., \& Hafedh, H. (2017). Accuracy assessment of different gnss processingsoftware. Imperial Journal of Interdisciplinary Research, 3(10), 469-478.

[18] Isioye, O. A., Moses, M., \& Abdulmumin, L. (2019). Comparative study of some online gnss post processing services at selected permanent gnss sites in Nigeria." Accuracy of GNSS Methods,(Online). Intech Open, London, EC3R 6AF, UK, Chapter 6, 90-106.

[19] Experiment stations in USA log files and datas. Accessed 26 June, 2019. http://sopac.ucsd.edu.

[20] Experiment stations in Turkey log files. Accessed 01 September, 2019.

[21] Experiment stations in Turkey log files. Accessed 01 September, 2019. https://ukbs.iski.gov.tr/

[22] Weahter forecast. Accessed 27 July, 2019. www.solarham.net.

[23] Atmopheric forecast. Accessed 27 July, 2019. www.swpc.noaa.gov.

[24] KP index. Accessed 30 July, 2019. www.gfz-potsdam.de.

[25] Atmopheric forecast. Accessed 27 July, 2019. www.weatherspark.com

[26] OPUS web service. Accessed 01 August,2019. https://www.ngs.noaa.gov/OPUS/index.jsp.

[27] CSRS-PPP web service. Accessed 26 July, 2019. https://webapp.geod.nrcan.gc.ca/geod/tools-outils/ppp.php.

[28] IGS stations, ephemeris datas. Accessed 29 July, 2019. https://www.igs.org

Contact information:

Tuna EROL, PhD

Balikesir University, Rectorate Construction and Technical Directorate,

Balikesir University ,Çağış Campus, Rectorate Bulding 2th Floor, 10145, Turkey

Contact Tel: +90266 6121425

E-mail: tunaerol@balikesir.edu.tr; tunaerol@hotmail.com 